\title{
Age, pathogen exposure, but not maternal care shape offspring immunity in an insect with facultative family life
}

\author{
Fanny Vogelweith ${ }^{1 *+}$, Maximilian Körner ${ }^{1 \dagger}$, Susanne Foitzik ${ }^{1}$ and Joël Meunier ${ }^{1,2}$
}

\begin{abstract}
Background: To optimize their resistance against pathogen infection, individuals are expected to find the right balance between investing into the immune system and other life history traits. In vertebrates, several factors were shown to critically affect the direction of this balance, such as the developmental stage of an individual, its current risk of infection and/or its access to external help such as parental care. However, the independent and/or interactive effects of these factors on immunity remain poorly studied in insects.

Results: Here, we manipulated maternal presence and pathogen exposure in families of the European earwig Forficula auricularia to measure whether and how the survival rate and investment into two key immune parameters changed during offspring development. The pathogen was the entomopathogenic fungus Metarhizium brunneum and the immune parameters were hemocyte concentration and phenol/pro-phenoloxidase enzyme activity (total-PO). Our results surprisingly showed that maternal presence had no effect on offspring immunity, but reduced offspring survival. Pathogen exposure also lowered the survival of offspring during their early development. The concentration of hemocytes and the total-PO activity increased during development, to be eventually higher in adult females compared to adult males. Finally, pathogen exposure overall increased the concentration of hemocytes-but not the total-PO activity -in adults, while it had no effect on these measures in offspring.

Conclusions: Our results show that, independent of their infection risk and developmental stage, maternal presence does not shape immune defense in young earwigs. This reveals that pathogen pressure is not a universal evolutionary driver of the emergence and maintenance of post-hatching maternal care in insects.
\end{abstract}

Keywords: Developmental stage, Instar, Family life, Forficula auricularia, Insect immunity, Metarhizium brunneum, Trade-off

\section{Background}

Most living organisms are parasites [1]. By altering the growth, fecundity, and survival of their hosts, they represent a strong selective force that drives the evolution of multiple defense in their hosts [2]. To limit the costs of pathogen infections, hosts typically depend on their immune system [2]. In insects, an important part of this defense relies on the coordinate action of non-specific and constitutive mechanisms, among which textbook examples involve hemocytes and phenoloxidase [3].

\footnotetext{
* Correspondence: fanny.vogelweith@gmail.com

${ }^{\dagger}$ Equal contributors

'Zoological Institute, Evolutionary Biology, Johannes-Gutenberg University of

Mainz, Mainz, Germany

Full list of author information is available at the end of the article
}

Hemocytes are immune cells that circulate in the hemolymph and are involved in recognition and encapsulation of pathogens [4]. Conversely, phenoloxidase mostly mediates the melanization of foreign objects and operates through the activation of the prophenoloxidase cascade, its inactive precursor typically stored in the hemolymph and the hemocytes [5].

Investing into immunity is costly and individuals are thus expected to adjust this investment to their current risk of infection, their general condition and/or their potential access to external help provided by group members [6]. Many vertebrates and invertebrates were shown to prophylactically increase their investment into immunity when the risk of infection is high, e.g. due to the presence of pathogens or of possibly infected individuals 
in their vicinity [7-9]. For example, populations of the small ground finch Geospiza fuliginosa that lived on islands with a high parasite prevalence invested more in their immune system compared to birds under low parasite pressure [10]. Conversely, individuals from the same species/population experiencing favorable conditions either during development and/or adult life are also often able to invest more into energetically costly traits, such as immune defenses $[11,12]$. In line with this prediction, large and/or well-nourished individuals are typically known to exhibit higher concentrations of immune components in their blood or hemolymph than small and light ones at the population level [12, 13]. Finally, how much an individual invests into its immunity may also depend on the help it has received or will receive from others, i.e. on the expression of social immunity $[14,15]$. Social immunity is a well-studied phenomenon in eusocial insects, where it can take multiple forms such as allo-grooming and hygienic behaviors [14, 16], but is also known to play a central role in simple family units via parental care. The effect of parental care on offspring immunity is well documented in vertebrates, with examples showing that post-hatching parental care enhances the immune response of young barn swallows Hirundo rustica [17] or that parental deprivation reduces the immunocompetence of juveniles in mice [18] and rats [19]. Comparatively, the effects of post-hatching parental care on offspring immunity are less clear in invertebrates, with only one study showing that parental deprivation reduces the lytic activity of larval exudate-a mediator of social immunity-in the burying beetle Nicrophorus vespilloides [20].

Interestingly, the influence of parental care on offspring immunity may depend on the age of the offspring and their risks of pathogen infection. In many vertebrates and invertebrates, immunocompetence increases during development [21-24]. Consequently, the effects of parental care on offspring immunity could be limited to the early stages of development (when parents interact with their juveniles) and then disappear when these juveniles have developed their own immune defenses. On the other hand, parental care facilitates offspring development with effects often reaching into adulthood, so that immune defenses could still be altered long after parents stopped caring for their offspring. Finally, the risk of infection could also determine how much parents invest into the care of their juveniles [25] and thus how much the offspring can invest into their own immune defense. For instance, the presence of pathogens in the environment has been shown to increase the expression of parental care in the frog Hylophorbus rufescens, as well as in humans, which in turn results in higher survival rates of pathogen-exposed offspring $[26,27]$.
In this study, we investigated the simultaneous and interactive effects of early maternal presence, early exposure to pathogens and developmental stage on offspring immunity in the European earwig Forficula auricularia. In this insect, females provide multiple forms of care to their juveniles (called nymphs) during 2 weeks following egg hatching, such as food provisioning, allo-grooming and protection against predators [28]. Nevertheless, earwig nymphs are mobile, can forage on their own and are thus typically capable to develop and survive in the absence of a tending mother $[28,29]$. Here, we conducted a $2 \times 2$ full-factorial experiment in which we manipulated the presence or absence of a mother, as well as the presence or absence of the entomopathogenic fungus Metarhizium brunneum in the nest during the two first weeks post egg hatching (i.e. the period of family life). We then measured nymph survival and immune defenses at the 2nd, 3rd and 4th developmental instars, as well as in the adults. Overall, we expect that maternal presence improves the short- and long-term survival of offspring reared in a previously contaminated nest. In terms of immunity, we predict that this positive effect of maternal presence translates in either a maternally-driven increase in the offspring's capability to invest into personal immune defenses (for instance due to the early accumulation of maternallyprovided resources) or a maternally-driven decrease of offspring' investment into personal immunity (the immune protection ensured by maternal care could allow nymphs to shift their investment from immunity to other important traits such as growth). Finally, if maternal care has limited or no effect on offspring immunity, we predict offspring immune defenses to increase with age and with early pathogen exposure, but these effects to be independent of early maternal presence.

\section{Methods \\ Insects rearing}

Adult $F$. auricularia earwigs were caught in July-August 2015 in Mainz, Germany (49 58'20.5"N 8¹1'42.3"E). Immediately after field sampling, earwigs were distributed among plastic containers $(37 \times 22 \times 25 \mathrm{~cm})$ grounded with humid sand. These adults were then allowed to mate freely for 4 months. Thereafter, all females were removed from their containers to mimic dispersal, a behavior they typically express under natural condition prior to egg laying [30]. The females were isolated in Petri dishes $(9 \mathrm{~cm}$ diameter) that were furnished with moist sand, maintained under winter conditions $\left(15^{\circ} \mathrm{C}\right.$ in darkness) and provided with a diet of ad libitum standard food (food composition detailed in [31]). Each Petri dish was then checked twice a week for eggs. Food provisioning was stopped when eggs were found, as females typically cease to feed between egg laying and hatching [28]. At egg 
hatching, all clutches were transferred to and maintained under summer conditions $\left(18-20^{\circ} \mathrm{C} \mathrm{D}: \mathrm{L}\right)$ until the end of the experiment (conditions detailed in [32]).

\section{Experimental design}

A total of 98 clutches were used to measure the effects of early maternal presence and/or early pathogen exposure on two immune parameters on nymphs and young adults. Each clutch was culled to 35 nymphs 1 day after hatching (i.e. 1st instar nymphs) and then transferred to Petri dishes either with (1) their own mother and contaminated sand $(n=25),(2)$ their own mother and non-contaminated sand $(n=24),(3)$ no mother and contaminated sand $(n=25)$ or (4) no mother and non-contaminated sand $(n=24)$. The contaminated and non-contaminated sands were created by preliminary grounding each recipient Petri dish $(9 \mathrm{~cm}$ diameter) with humid sand and then sprinkling the sand with either $100 \mu \mathrm{l}$ of a conidiospore solution of M. brunneum diluted in $0.05 \%$ Tween $\left(10^{7}\right.$ spores $\left./ \mathrm{ml}\right)$ or with 100 $\mu \mathrm{l}$ of a control spore-free solution of $0.05 \%$ Tween, respectively. M. brunneum is a common entomophagous fungus in the soil, which is known to infect and reduce the survival of a wide range of insects (including earwigs) in nature, but against which the roles of hemocyte concentration and phenoloxidase activity remain largely unclear [33-35]. On day 14 after egg hatching, all tending mothers were removed from their group of nymphs (when applicable) to mimic natural family dispersal [29]. Six days later, each group of nymphs was transferred to a large Petri dish (14 cm diameter) grounded with noncontaminated sand and maintained as such until they reach adulthood. Note that adult males and females produced in each family were separated at emergence to ensure virginity and avoid inbreeding at the time of immune measurements (see below) [36]. All animals were provided with an ad libitum amount of standard food changed twice a week (detailed food composition in [31]).

We followed offspring survival during their development by counting all group members either five (2nd, 3rd and 4th developmental instar) or ten (adults) days after the first individual of each clutch molted into the next developmental instar. Note that 1st instar nymphs molt into their 2nd instar approximately 12 days after egg hatching [32, 37]. The days five and ten were chosen to ensure that (almost) all group members reached the new instar (or adulthood) on the day of counting (see details on developmental times in [38]). After counting, we randomly sampled two nymphs per developmental instar (and one adult male and one adult female per group), weighed these individuals to the nearest $0.001 \mathrm{mg}$ using a microscale (model MYA5; PESCALE, Bisingen, Germany), and used them for immune measurements (see below). Note that these animals were subtracted for the calculation of survival rates.

\section{Measurement of the two immune parameters}

We measured two key immune parameters in 2nd, 3rd and 4th instar nymphs, as well as in adult males and females: the total-PO activity and the concentration of circulating hemocytes. Total-PO activity was defined as the sum of phenoloxidase (PO) and prophenoloxidase (PPO) activities, therefore reflecting the immunocompetence of an individual in terms of both already activated and notyet activated phenoloxidase enzymatic cascade. Note that earwig individuals cannot be sexed until they reach adulthood. In each of the two nymphs sampled per instar, between 0.2 to $0.5 \mu \mathrm{l}$ of hemolymph was first extracted with a glass capillary, while $1 \mu \mathrm{l}$ was extracted in each adult male and female (see above). These extracts were immediately diluted in $11 \mu \mathrm{l}$ (for nymphs) or $25 \mu \mathrm{l}$ (for adults) of cold sodium cacodylate $/ \mathrm{CaCl}_{2}$ buffer $(0.01$ $\mathrm{M}$ sodium cacodylate, $0.005 \mathrm{M} \mathrm{CaCl} 2 ; \mathrm{pH} 6.5)$ to measure the two immune parameters.

The concentration of all hemocytes (i.e. independent of their type and thus of their specific immune function) was measured immediately after hemolymph extraction, using $10 \mu \mathrm{l}$ of diluted hemolymph of the nymph and 10 $\mu \mathrm{l}$ of the diluted hemolymph of each male and female. This counting was done using a Neubauer Improved Haemocytometer and a microscope (magnification $\mathrm{x}$ 400), as described in [39].

Total-PO activity was spectrophotometrically measured using a standard protocol described in [39]. Specifically, the diluted hemolymph of one nymph (volume $=1.5 \mu \mathrm{l})$ and $16 \mu \mathrm{l}$ remaining of the diluted hemolymph of each male and female were frozen at $-30^{\circ} \mathrm{C}$ to optimize the measurement of total-PO activity. Each sample of frozen hemolymph was then thawed on ice and centrifuged for $5 \mathrm{~min}$ at $4^{\circ} \mathrm{C}(4000 \times \mathrm{g})$. Five $\mu \mathrm{l}$ of the resulting supernatant was then added to a microplate well containing $20 \mu \mathrm{l}$ of PBS and $140 \mu \mathrm{l}$ of chymotrypsin solution (Sigma C-7762, $0.07 \mathrm{mg} / \mathrm{ml}$ of distilled water). A volume of $20 \mu \mathrm{l}$ of L-dopa solution (Sigma D-9628; 4 $\mathrm{mg} / \mathrm{ml}$ of distilled water) was then added to each well. The reaction was allowed to proceed for $2 \mathrm{~h} 47 \mathrm{~min}$ at $30^{\circ}$ $\mathrm{C}$ in a microplate reader (Thermo scientific Multiskan ${ }^{\mathrm{m}}$ FC Microplate Photometer). Enzyme activity was defined as the slope of the reaction curve during the linear phase of the reaction (Vmax value: change in absorbance units/min) and measured using the R-based program PO-CALC [40]. All immune measurements were done blind regarding the early presence of the mother and the early exposure to pathogens.

Because the volume of extracted hemolymph and the resulting concentration of hemocytes slightly change between individuals, we standardized the concentration of 
hemocytes and total-PO activity (immune parameters) per microliter of hemolymph using the following formula: $\mathrm{I} x[(\mathrm{Vh}+\mathrm{Vb}) / \mathrm{Vh}] / \mathrm{Vm}$, in which $\mathrm{I}$ is the measured immune parameter, $V h$ is the volume of extracted hemolymph, $\mathrm{Vb}$ is the volume of buffer added (i.e. $11 \mu \mathrm{l}$ for nymphs or $25 \mu \mathrm{l}$ for adults) and $\mathrm{Vm}$ is the volume applied either to the Haemocymeter for hemocyte count (i.e. $10 \mu \mathrm{l}$ ) or on the spectrophotometer plate for totalPO measurement (i.e. $5 \mu \mathrm{l}$ ).

\section{Statistical analyses}

All statistical analyses were conducted using the software R v3.1.2 loaded with the packages car, lme4, MASS and lsmeans. The survival rate in between each developmental stage (defined here as "age") of offspring (entered using the cbind function) was tested using a generalized linear mixed-effects model (GLMM, with binomial error distribution). In this model, the age (second, third and fourth nymphal instars, and adults), early pathogen exposure (presence/absence) and early maternal presence (presence/absence) were entered as explanatory categorical factors, while the clutch identification (ID) was entered as a random factor to control for the fact that each clutch was used for each age. Because we interested in the survival rate of nymphs until their reach adulthood, adult males and females were pooled as "adults" in this model.

Immune parameters were then analyzed separately for nymphs (for which the sex was unknown) and adults (for which the sex was known). For each nymph and adult data set, hemocyte concentration and total-PO activity were analyzed using two LMMs, in which either the age of the nymphs (second, third and fourth nymphal instars) or the gender of the adults (male or female), early pathogen exposure, early maternal presence and the weight of the measured individual were entered as explanatory factors, whereas the ID was used as a random effect. In nymphs, the weight of each class of age was scaled and centered to correct for the inherent difference in weight between each instar. All models first included all interactions between the explanatory factors and were then simplified stepwise by removing the nonsignificant interaction terms (all $P$-values $>0.08$ ). Note that some non-significant interactions are presented here to allow direct comparisons between models, but their removal did not qualitatively change the results.

\section{Results}

The presence of a tending mother overall reduced the proportion of offspring that successfully reached adulthood, independent of pathogen exposure and age (Table 1; Fig. 1a). By contrast, offspring survival depended on an interaction between pathogen exposure and age (Table 1; Fig. 1b): the pathogenic fungus $M$.
Table 1 Effects of age, maternal presence and pathogen exposure on the survival rate of offspring

\begin{tabular}{lcl}
\hline & \multicolumn{2}{c}{ Survival } \\
\cline { 2 - 3 } & Chisq & p-value \\
\hline Age & 86.39 & $<\mathbf{0 . 0 0 0 1}$ \\
Maternal presence & 4.00 & $\mathbf{0 . 0 4 5}$ \\
Pathogen exposure & 6.21 & $\mathbf{0 . 0 1 3}$ \\
Age: Pathogen exposure & 14.87 & $\mathbf{0 . 0 0 2}$ \\
\hline
\end{tabular}

Significant $p$-values are in bold. Note that non-significant interactions are not reported in this table

brunneum reduced the survival rate of nymphs to the 2nd and 3rd instar, but did not affect their survival rate between the 3rd and 4th instars and was finally associated with an increased survival rate between the 4th instar and adulthood (Fig. 1b).

Overall, there were contrasting effects of pathogen exposure, maternal presence, body weight, offspring developmental stage and adult gender on hemocyte concentration and total-PO activity in offspring. Specifically, early pathogen exposure increased hemocyte concentration, but not total-PO activity in adults (Table 2; Figs. 2a and $3 \mathrm{a}$ ), whereas it did not affect these two immune parameters in nymphs (Table 3; Figs. $2 \mathrm{~b}$ and $3 \mathrm{~b}$ ). Early maternal presence also had no effect on the concentration of hemocytes and on the total-PO activity in both nymphs and adults (Tables 2 and 3; Figs. 2c, d and 3c and d). By contrast, the association between body weight and hemocyte concentration was positive in nymphs (Table 3; Fig. 4a; $\rho=-0.27$; C.I. $95 \%=[-0.38 ;-0.16]$ ), but negative in adults (Table 2; Fig. $4 b ; \rho=0.27$; C.I. $95 \%$ $=[0.11 ; 0.41])$. There was, however, no association between body weight and total-PO activity in nymphs and adults (Tables 2 and 3). Finally, the concentration of hemocytes and the total-PO activity increased between each nymphal instar (Table 3; Figs. 2f and 3f) and were higher in adult females compared to adult males (Table 2; Figs. 2e and 3e).

\section{Discussion}

This study aimed at elucidating the effects of early maternal presence and early exposure to pathogens on the immunity of growing offspring in the European earwig F. auricularia. Our results show that the presence of the mother during the first 2 weeks of life has no effect on the immunity of her offspring at both nymphal and adult stages. However, maternal presence generally reduced the survival of their offspring, a result in line with a previous study [38] and suggesting that the benefits of posthatching care in $F$. auricularia could generally take a form that is excluded from the current experimental setup (e.g. predator defense, thermal resistance). Conversely, we found that early pathogen exposure generally 

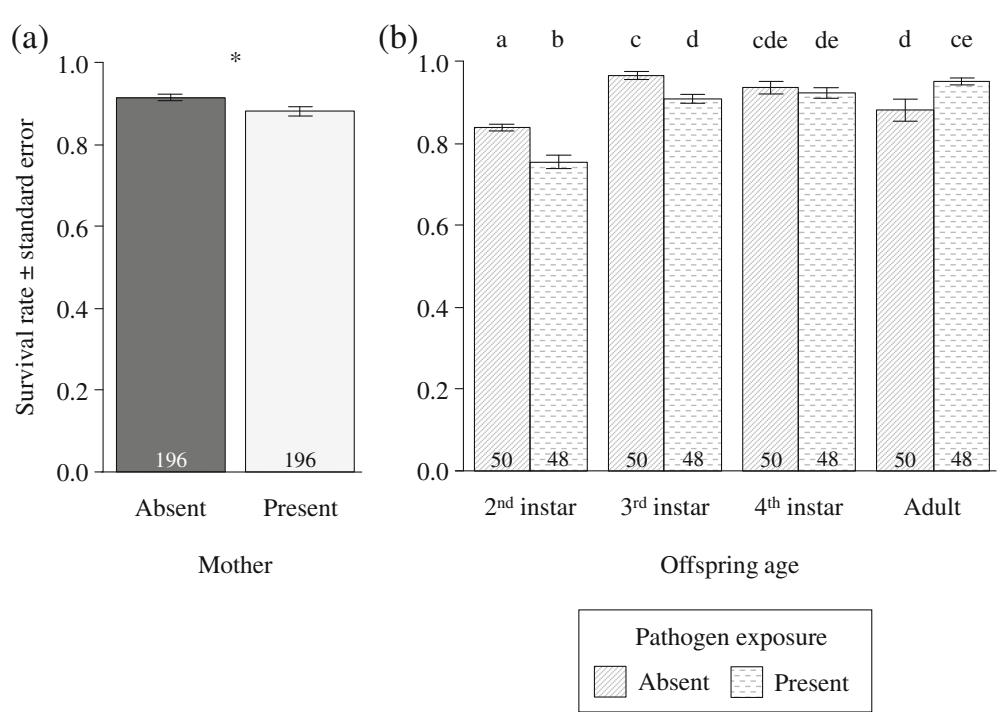

Fig. 1 Effects of maternal presence, offspring age and pathogen exposure on offspring survival rate. The fitted values are given in function of (a) maternal presence and of $(\mathbf{b})$ the interaction between pathogen exposure and offspring age in between each instar. Sample sizes are provided at the bottom of each bar. Different letters indicate statistically significant differences $(p<0.05) .{ }^{*} p<0.01$

increased the concentration of hemocytes-but not the total-PO activity-in adult offspring and had no effect on nymph's immunity. Both hemocyte concentration and total-PO activities increased with offspring development, and these two immune parameters were higher in adult females compared to adult males. Finally, pathogen exposure early in life caused low survival during the early developmental stages, while it increases adult survival.

Somewhat surprisingly, we found that maternal care has no long-lasting effects on offspring immunity. This result contrasts with other studies investigating short- or long- term effects of parental care/parental deprivation on offspring immunity in vertebrates $[17-19,41]$. For instance, nestling immunocompetence increased with parental care $24 \mathrm{~h}$ after an immune challenge in barn swallows Hirundo rustica [17], and a long-term decrease in immunity has been shown in adult mice earlydeprived of their mother [18]. The limited effects of maternal presence on offspring immunity reported here

Table 2 Effects of gender, maternal presence, pathogen exposure and weight on immune parameters in adults

\begin{tabular}{lllllll}
\hline & \multicolumn{2}{l}{ Hemocyte concentration } & & \multicolumn{2}{l}{ Total-PO activity } \\
\cline { 2 - 3 } & Chisq & $p$-value & & Chisq & $p$-value \\
\hline Gender & 3.97 & $\mathbf{0 . 0 4 6}$ & & 42.12 & $<\mathbf{0 . 0 0 0 1}$ \\
Maternal presence & 0.36 & 0.547 & & 1.18 & 0.278 \\
Pathogen exposure & 4.99 & $\mathbf{0 . 0 2 5}$ & & 2.25 & 0.133 \\
Weight & 7.38 & $\mathbf{0 . 0 0 6}$ & & 0.02 & 0.900 \\
\hline
\end{tabular}

Significant $p$-values are in bold. Note that non-significant interactions are not reported in this table therefore reveal that maternal presence does not necessarily shape the immunity of offspring in insects, and more generally that pathogens are not a universal selective pressure promoting maintenance of post-hatching maternal care in nature. Understanding whether this independence between parental care and offspring immunity is unique to earwig biology $[38,42,43]$ (e.g. juveniles are less dependent on maternal care in earwigs compared to most vertebrate and invertebrate species) or on the immune system of invertebrates in general [44] will require further studies exploring the expression and nature of this link across a larger set of species.

Early exposure to $M$. brunneum did not unmask the effect of maternal care on offspring immunity, which contrasts with a previous result demonstrating that maternal presence improves the survival of eggs exposed to fungal spores in this species [25]. However, we found an age-specific effect of pathogen exposure on offspring survival, which reflected a reduced survival rate between hatching and the 3rd instar, an absence of effect between 3rd and 4th instar and a higher survival rate between 4th instar and adulthood. This contrasting age-specific effect of pathogen exposure might reflect three nonmutually exclusive processes. First, juveniles could exhibit a weak immune activity (as reported in many vertebrate and invertebrate species, see for instance in reptiles [45] and in the honey bee [46]), making them less likely to survive pathogen exposure compared to older nymphs [3]. In line with this scenario, we found that the levels of total-PO and hemocyte concentrations increased with the developmental stage of the nymphs. Second, due to our experimental design the 2nd and 3rd 
(a)

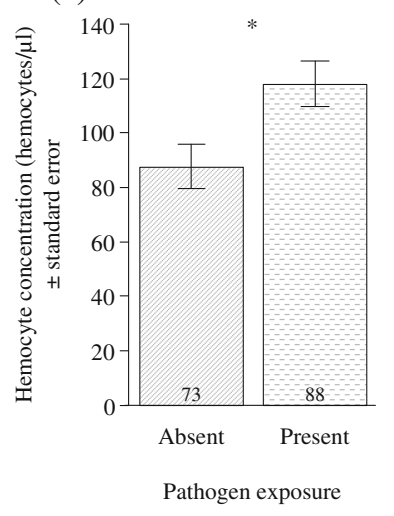

(b)

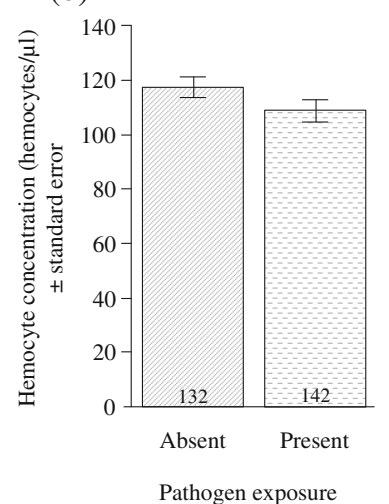

(c)

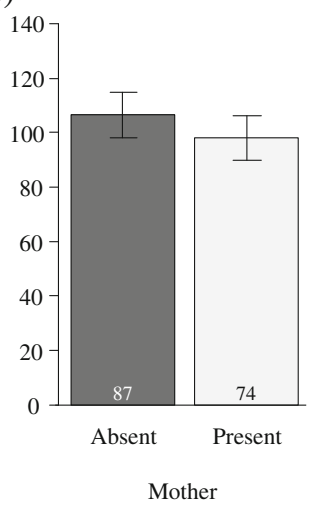

(d)

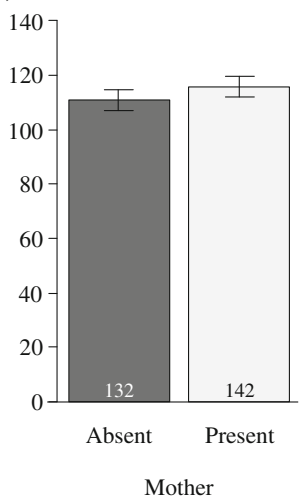

(e)

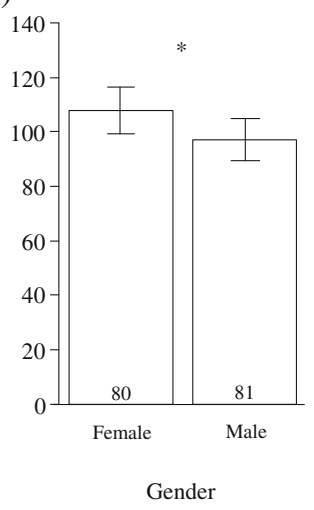

(f)

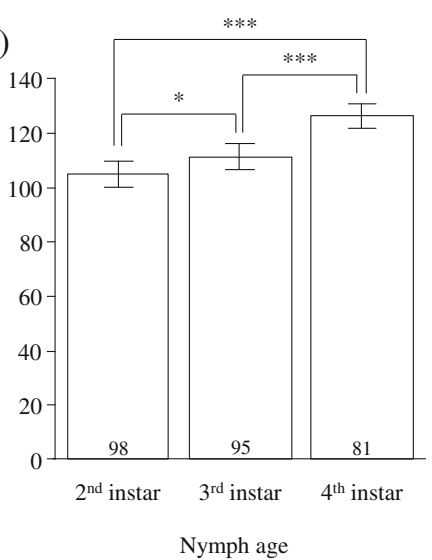

Fig. 2 Effects of pathogen exposure, maternal presence and adult gender or nymphal age on hemocyte concentration. The fitted values are given in function of $(\mathbf{a}, \mathbf{b})$ pathogen exposure, $(\mathbf{c}, \mathbf{d})$ maternal presence and $(\mathbf{e}, \mathbf{f})$ gender/nymph age in adults and nymphs, respectively. White bars represent age/gender, grey hatched/horizontal dotted bars represent the absence/presence of pathogen, and dark/light grey bars represent the absence/presence of mother. Sample sizes are provided at the bottom of each bar. ${ }^{* * *} p<0.0001$

developmental instars were chronologically the first instars emerging after pathogen exposure, which could have resulted in a higher proportion of live spores in the environment of young compared to old offspring and thus in a decreased risk of a novel infection in later instars. Finally, the survival of adults could reflect the early elimination of the weakest individuals in pathogen compared to control treatments, which entailed the production of better quality adults in the former case. To disentangle these three processes, further studies should thus investigate whether offspring exposed to a pathogen either at the beginning of each instar or only at their 1st instar exhibit different or similar survival rates and levels of immunity.

Besides the general increase of offspring's immunity over developmental stages, we found that the association between hemocyte concentration and individual weight was negative in nymphs, but positive in adults. Immunity is generally sustained by either increasing the acquisition of food resources or by reducing energy allocation to other physiological processes such as growth and reproduction [2, 47] (see for examples [17, 47-49]). However, variation in the amount of resources available to an individual is known to possibly mask investment trade-offs between mutually exclusive functions and even to produce positive associations between these functions at a population level $[42,50,51]$. The apparent discrepancy between the presence of a trade-off in nymphs and of a positive association in adults therefore suggests that investing into immunity is generally costly in earwigs, but that this cost is masked in adults-possibly due to a higher variation in resource acquisition between adults compared to between nymphs. Investigating variation in foraging strategies and food intake of nymph and adult earwigs, and thus their role in immune investment will be done in the future. This notwithstanding, our results also reveal that maternal presence does not limit the costs of immune investment, further stressing the limited effects of maternal care on offspring immunity. 

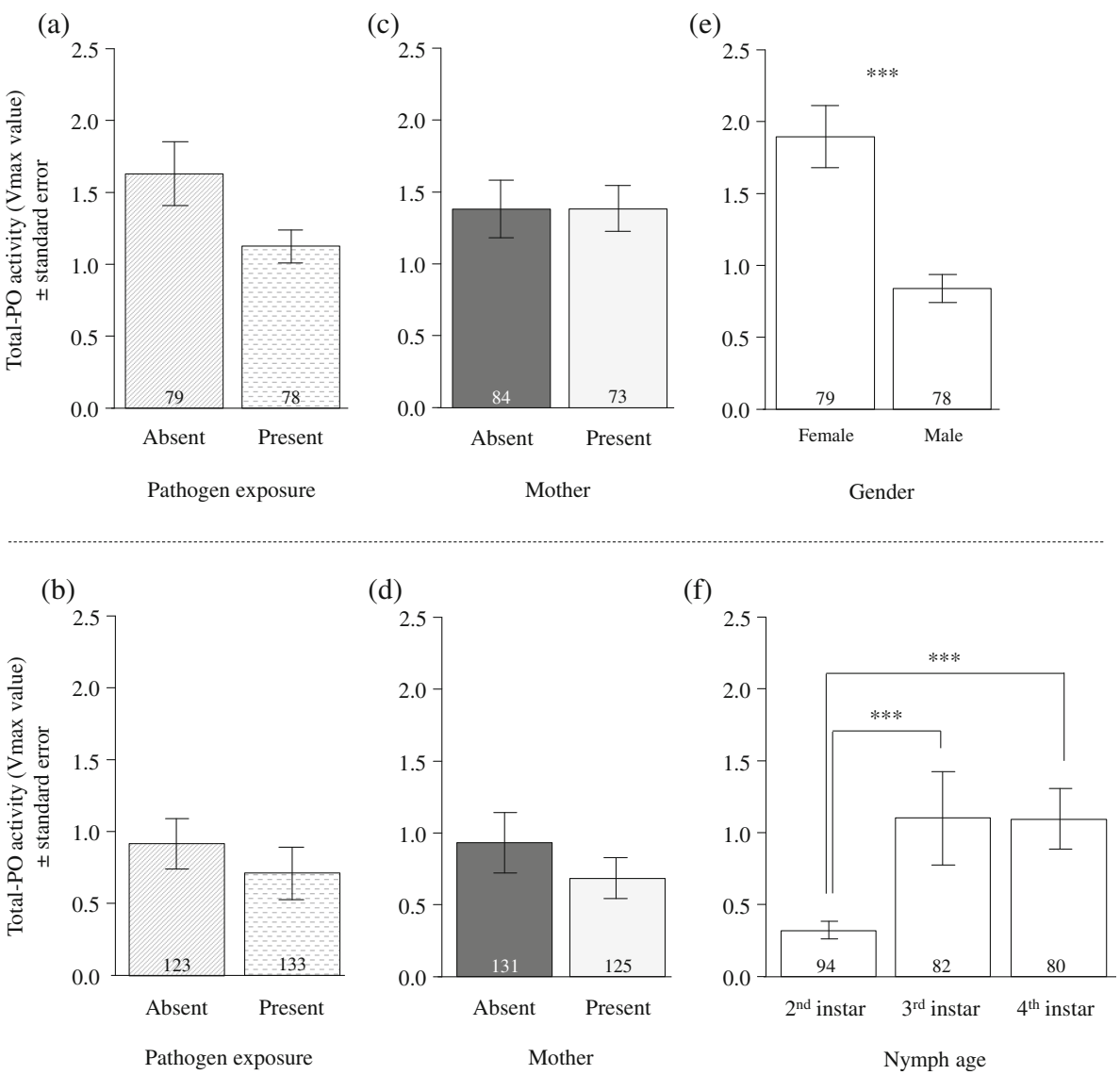

Fig. 3 Effects of pathogen exposure, maternal presence and adult gender or nymphal age on total-PO activity. The fitted values are given in function of $(\mathbf{a}, \mathbf{b})$ pathogen exposure, $(\mathbf{c}, \mathbf{d})$ maternal presence and $(\mathbf{e}, \mathbf{f})$ gender/nymph age in adults and nymphs, respectively. Sample sizes are provided at the bottom of each bar. ${ }^{* *} p<0.0001$

Independent of body weight, our results finally showed that adult females had more hemocytes and a higher total-PO activity than adult males. This sex-specific investment into immune components is in line with results found across many insect species, such as butterflies [52], crickets [53], dragonflies [54], flies [55] and scorpionflies [56]. In earwigs, males are known to survive only for a single reproductive period (i.e. a few months). By contrast, females live up to 1.5 years, during which they provide care to their eggs for several months,

Table 3 Effects of age, maternal presence, pathogen exposure and weight on immune parameters in nymphs

\begin{tabular}{llllll}
\hline & \multicolumn{2}{l}{ Hemocyte concentration } & & \multicolumn{2}{l}{ Total-PO activity } \\
\cline { 2 - 3 } & Chisq & $p$-value & & Chisq & $p$-value \\
\hline Age & 12.65 & $\mathbf{0 . 0 0 1}$ & & 74.47 & $<\mathbf{0 . 0 0 0 1}$ \\
Maternal presence & 0.41 & 0.520 & & 0.12 & 0.732 \\
Pathogen exposure & 0.17 & 0.681 & & 0.61 & 0.436 \\
Weight & 18.71 & $<\mathbf{0 . 0 0 0 1}$ & & 0.13 & 0.721 \\
\hline
\end{tabular}

Significant $p$-values are in bold. Note that non-significant interactions are not reported in this table provide care to the resulting nymphs for several weeks and then often produce a second clutch which they care for during several additional weeks [32, 37]. Compared to males, females fitness is therefore tightly associated with their capability to survive over several seasons and thus to fight against longer and/or more frequent attacks by pathogens, overall likely explaining their higher investment into immune defense (see also [33]).

\section{Conclusions}

Our results overall reveal that age, gender and parasite exposure shape the immune system of the European earwig $F$. auricularia, while the presence of a caring mother did not. Personal immunity and social immunity in the form of maternal care are nevertheless not the only protection against pathogens that can operate within family units [16]. For instance, larvae can participate in social immunity and thus provide immune benefits to their siblings by sanitizing the nest with anal exudates, a phenomenon reported in the burying beetle $N$. vespilloides [57] and importantly, in the European earwig $F$. auricularia [58]. Our findings therefore reveal that for 
(a)

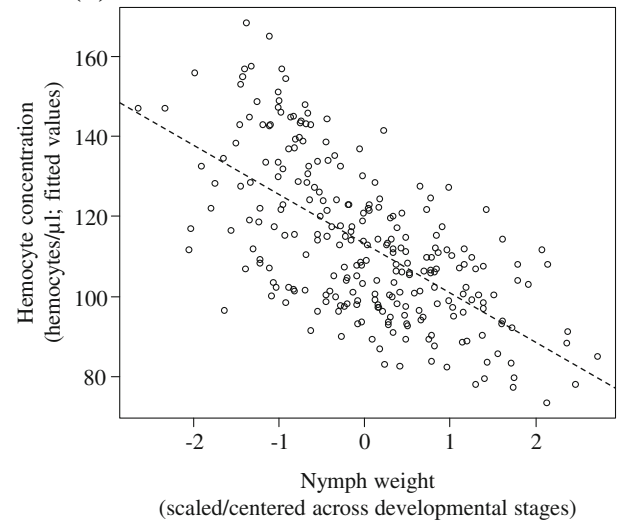

(b)

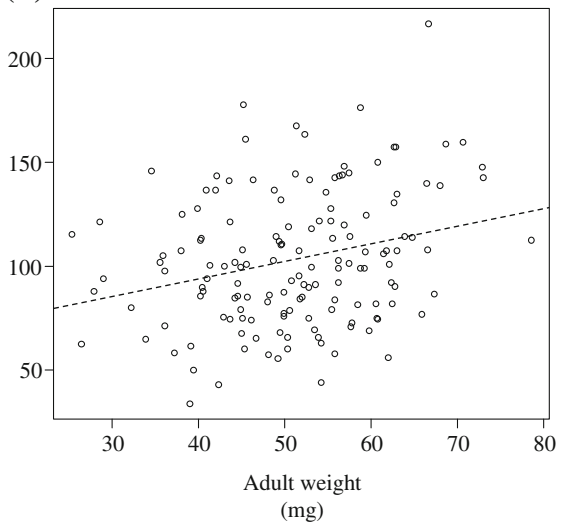

Fig. 4 Correlation between hemocyte concentration and the weight in (a) nymphs and (b) adults. The hemocyte concentration are fitted values obtained from the LMMs. In nymphs, the weight of each class of age was scaled and centered to correct for the inherent difference in weight between each instar. Each dot represents an individual and the dash line represents correlation between hemocyte concentration and weight

nymphs, the net benefits of family interactions in terms of protection against pathogen infection are unlikely to come from the mothers, but could instead result from the presence and/or interactions with their siblings. Hence, our findings overall call for further studies investigating the role of sibling behaviors, together with age, gender and parasite exposure, in the emergence and maintenance of family life in nature.

\section{Acknowledgements}

We thank Armin Joos and Jos Kramer for their technical assistance. We also thank the four anonymous reviewers for their helpful comments.

\section{Funding}

This study has been financed by the Alexander von Humboldt Foundation (to FV) and by the German Science Foundation (DFG; ME4179/3-1 to JM).

\section{Availability of data and material}

Data available from the Dryad Digital Repository: http://dx.doi.org/10.5061/ dryad.44181.

\section{Authors' contributions}

FV, MK, SF and JM conceived the experiments; FV and MK performed the experiment; FV and JM performed the statistical analysis; SF provided lab facilities; FV and JM wrote the first draft of the manuscript. All authors helped to improve the final manuscript. All authors read and approved the final manuscript.

\section{Competing interests}

The authors declare that they have no competing interests.

\section{Consent for publication}

Not applicable

\section{Ethics approval and consent to participate}

Not applicable

\section{Author details}

'Zoological Institute, Evolutionary Biology, Johannes-Gutenberg University of Mainz, Mainz, Germany. ${ }^{2}$ Institut de Recherche sur la Biologie de I'Insecte, UMR CNRS 7261, François-Rabelais University of Tours, Tours, France.
Received: 12 December 2016 Accepted: 23 February 2017

Published online: 07 March 2017

\section{References}

1. Schmid-Hempel P. The diversity and natural history of parasites. Evol. Parasitol. Oxford: Oxford University Press; 2011. p. 18-51.

2. Zuk M, Stoehr AM. Immune defense and host life history. Am Nat. 2002 160(Suppl):S9-22

3. Siva-Jothy MT, Moret $Y$, Rolff J. Insect immunity: an evolutionary ecology perspective. Adv Insect Phys. 2005:32:1201-1248.

4. Lavine MDD, Strand MRR. Insect hemocytes and their role in immunity. Insect Biochem Mol Biol. 2002:32:1295-309.

5. Cerenius $L$, Söderhäll K. The prophenoloxidase-activating system in invertebrates. Immunol Rev. 2004;198:116-26.

6. Armitage SAO, Thompson JJW, Rolff J, Siva-Jothy MT. Examining costs of induced and constitutive immune investment in Tenebrio molitor. J Evol Biol Blackwell Science Ltd. 2003;16:1038-44.

7. Barnes Al, Siva-Jothy MT, Royal THE. Density-dependent prophylaxis in the mealworm beetle Tenebrio molitor $\mathrm{L}$ (Coleoptera: Tenebrionidae): cuticular melanization is an indicator of investment in immunity. Proc R Soc B Biol Sci. 2000;267:177-82.

8. Cotter SC, Hails RS, Cory JS, Wilson K. Density-dependent prophylaxis and condition-dependent immune function in Lepidopteran larvae: a multivariate approach. J Anim Ecol. 2004;73:283-93.

9. Ruiz-González MX, Moret Y, Brown MJF. Rapid induction of immune densitydependent prophylaxis in adult social insects. Biol Lett. 2009;5:781-3.

10. Lindström KM, Foufopoulos J, Pärn H, Wikelski M. Immunological investments reflect parasite abundance in island populations of Darwin's finches. Proc R Soc B Biol Sci. 2004;271:1513-9.

11. Westneat DF, Birkhead TR. Alternative hypotheses linking the immune system and mate choice for good genes. Proc R Soc B Biol Sci. 1998;265:1065-73.

12. Cotter SC, Kruuk LEB, Wilson K. Costs of resistance: Genetic correlations and potential trade-offs in an insect immune system. J Evol Biol. 2004;17:421-9.

13. Vogelweith F, Thiery D, Moret $Y$, Moreau J. Immunocompetence increases with larval body size in a phytophagous moth. Physiol Entomol. 2013;38:219-25.

14. Cremer S, Armitage SAO, Schmid-Hempel P. Social Immunity. Curr Biol. 2007;17:693-702.

15. Cotter SC, Kilner RM. Personal immunity versus social immunity. Behav Ecol. 2010:21:663-8.

16. Meunier J. Social immunity and the evolution of group living in insects. Philos Trans R Soc London B Biol Sci. 2015:370:20140102.

17. Saino N, Calza S, Moller AP. Immunocompetence of nestling Barn Swallows in relation to brood size and parental effort. J Anim Ecol. 1997:66:837-836.

18. Michaut R-J, Dechambre R-P, Doumerc S, Lesourd B, Devillechabrolle A, Moulias R. Influence of early maternal deprivation on adult humoral immune response in mice. Physiol Behav. 1981;26:189-91. 
19. von Hoersten S, Dimitrijević M, Marković BM, Janković BD. Effect of early experience on behavior and immune response in the rat. Physiol Behav. 1993;54:931-40.

20. Reavey CE, Beare L, Cotter SC. Parental care influences social immunity in burying beetle larvae. Ecol Entomol. 2014;39:395-8.

21. DeVeale B, Brummel T, Seroude L. Immunity and aging: The enemy within? Aging Cell. 2004;3:195-208.

22. Pletcher SD, Macdonald SJ, Marguerie R, Certa U, Stearns SC, Goldstein DB, et al. Genome-wide transcript profiles in aging and calorically restricted Drosophila melanogaster. Curr Biol. 2002;12:712-23.

23. Laughton AM, Boots M, Siva-Jothy MT. The ontogeny of immunity in the honey bee, Apis mellifera L. following an immune challenge. J. Insect Physiol. 2011;:57:1023-32.

24. Trauer U, Hilker M. Parental legacy in insects: variation of transgenerational immune priming during offspring development. PLoS One. 2013;8:e63392.

25. Boos S, Meunier J, Pichon S, Kölliker M. Maternal care provides antifungal protection to eggs in the European earwig. Behav Ecol. 2014;25:754-61.

26. Quinlan RJ. Human parental effort and environmental risk. Proc Biol Sci. 2007;274:121-5.

27. Bickford DP. Differential parental care behaviors of arboreal and terrestrial microhylid frogs from Papua New Guinea. Behav Ecol Sociobiol. 2004;55:402-9.

28. Kölliker M. Benefits and costs of earwig (Forficula auricularia) family life. Behav Ecol Sociobiol. 2007:61:1489-97.

29. Meunier J, Kölliker M. When it is costly to have a caring mother: food limitation erases the benefits of parental care in earwigs. Biol Lett. 2012;8:547-50.

30. Lamb RJ. Effects of dispersion, travel, and environmental heterogeneity on populations of earwig Forficularia auricularia L. Can J Zool. 1975;53:1855-67.

31. Kramer J, Thesing J, Meunier J. Negative association between parental care and sibling cooperation in earwigs: A new perspective on the early evolution of family life? J Evol Biol. 2015;28:1299-308.

32. Ratz T, Kramer J, Veuille M, Meunier J. The population determines whether and how life-history traits vary between reproductive events in an insect with maternal care. Oecologia. 2016;182:443-52.

33. Kohlmeier $\mathrm{P}$, Holländer $\mathrm{K}$, Meunier J. Survival after pathogen exposure in group-living insects: Don't forget the stress of social isolation! J Evol Biol. 2016;29:1867-72.

34. Konrad M, Vyleta ML, Theis FJ, Stock M, Tragust S, Klatt M, et al. Social transfer of pathogenic fungus promotes active immunisation in ant colonies. PLoS Biol. 2012;10:e1001300.

35. Denier D, Bulmer MS. Variation in subterranean termite susceptibility to fatal infections by local Metarhizium soil isolates. Insectes Soc. 2015;62:219-26.

36. Meunier J, Kölliker M. Inbreeding depression in an insect with maternal care: influences of family interactions, life stage and offspring sex. J Evol Biol. 2013;26:2209-20.

37. Meunier J, Wong JWY, Gomez Y, Kuttler S, Rollin L, Stucki D, et al. One clutch or two clutches? Fitness correlates of coexisting alternative female life-histories in the European earwig. Evol Ecol. 2012;26:669-82.

38. Thesing J, Kramer J, Koch LK, Meunier J. Short-term benefits, but transgenerational costs of maternal loss in an insect with facultative maternal care. Proc R Soc B Biol Sci. 2015;282:20151617.

39. Vogelweith F, Thiéry $D$, Quaglietti $B$, Moret $Y$, Moreau J. Host plant variation plastically impacts different traits of the immune system of a phytophagous insect. Funct Ecol. 2011;25:1241-7.

40. Kohlmeier P, Dreyer H, Meunier J. PO-CALC: A novel tool to correct common inconsistencies in the measurement of phenoloxidase activity. J Insect Physiol. 2015;75:80-4.

41. Brown GP, Shine R. Maternal body size influences offspring immune configuration in an oviparous snake. R Soc Open Sci. 2016;3:160041.

42. Koch LK, Meunier J. Mother and offspring fitness in an insect with maternal care: phenotypic trade-offs between egg number, egg mass and egg care. BMC Evol Biol. 2014;14:125

43. Kölliker M, Boos S, Wong JWY, Röllin L, Stucki D, Raveh S, et al. Parentoffspring conflict and the genetic trade-offs shaping parental investment. Nat Commun. 2015;6:6850

44. Beckage NE. Insect Immunology. Oxford: Elsevier Inc; 2008. p. 348.

45. El Deeb SO, Saad AHM. Ontogenic maturation of immune system in reptiles. Dev Comp Immunol. 1990;14:151-9.

46. Wilson-Rich N, Dres ST, Starks PT. The ontogeny of immunity: Development of innate immune strength in the honey bee (Apis mellifera). J Insect Physiol. 2008:54:1392-9.
47. Schmid-Hempel P. Evolutionary ecology of insect immune defenses. Annu Rev Entomol. 2005;50:529-51.

48. Vogelweith F, Dourneau M, Thiéry D, Moret Y, Moreau J. Geographical variation in parasitism shapes larval immune function in a phytophagous insect. Naturwissenschaften. 2013;100:1149-61.

49. Brommer JE. Immunocompetence and its costs during development: an experimental study in blue tit nestlings. Proc R Soc B-Biological Sci. 2004;271:S110-3.

50. van Noordwijk AJ, de Jong G. Acquisition and allocation of resources: their influence on variation in life history tactics. Am Nat. 1986;128:137-42.

51. Parker GA, Begon M. Optimal egg size and clutch size: effects of environment and maternal phenotype. Am Nat. 1986;128:573-92.

52. Stoehr AM. Inter- and intra-sexual variation in immune defence in the cabbage white butterfly, Pieris rapae L.(Lepidoptera: Pieridae). 2007. p. 188-93.

53. Adamo $S A$, Jensen $M$, Younger $M$. Changes in lifetime immunocompetence in male and female Gryllus texensis (formerly G. integer): trade-offs between immunity and reproduction. Anim Behav. 2001;62:417-25.

54. Rolff J. Bateman's principle and immunity. Proc Biol Sci. 2002;269:867-72.

55. Mckean KA, Nunney L. Bateman's Principle and Immunity: phenotypically plastic reproductive Strategies predict changes in immunological sex differences. 2005;59:1510-7.

56. Kurtz J, Wiesner A, Götz P, Sauer KP. Gender differences and individual variation in the immune system of the scorpionfly Panorpa vulgaris (Insecta: Mecoptera). Dev Comp Immunol. 2000;24:1-12.

57. Arce AN, Smiseth PT, Rozen DE. Antimicrobial secretions and social immunity in larval burying beetles, Nicrophorus vespilloides. Anim Behav. 2013;86:741-5.

58. Diehl JM, Körner M, Pietsch M, Meunier J. Feces production as a form of social immunity in an insect with facultative maternal care. BMC Evol Biol. 2015;15:40.

\section{Submit your next manuscript to BioMed Central and we will help you at every step:}

- We accept pre-submission inquiries

- Our selector tool helps you to find the most relevant journal

- We provide round the clock customer support

- Convenient online submission

- Thorough peer review

- Inclusion in PubMed and all major indexing services

- Maximum visibility for your research

Submit your manuscript at www.biomedcentral.com/submit

) Biomed Central 